\title{
ARTICLE
}

Received 27 Nov 2015 | Accepted 6 Feb 2017 | Published 4 Apr $2017 \quad$ DOl: 10.1038/ncomms14845 OPEN

\section{Future climate forcing potentially without precedent in the last 420 million years}

\author{
Gavin L. Foster ${ }^{1}$, Dana L. Royer ${ }^{2} \&$ Daniel J. Lunt ${ }^{3}$
}

The evolution of Earth's climate on geological timescales is largely driven by variations in the magnitude of total solar irradiance (TSI) and changes in the greenhouse gas content of the atmosphere. Here we show that the slow $\sim 50 \mathrm{Wm}^{-2}$ increase in TSI over the last $\sim 420$ million years (an increase of $\sim 9 \mathrm{Wm}^{-2}$ of radiative forcing) was almost completely negated by a long-term decline in atmospheric $\mathrm{CO}_{2}$. This was likely due to the silicate weatheringnegative feedback and the expansion of land plants that together ensured Earth's long-term habitability. Humanity's fossil-fuel use, if unabated, risks taking us, by the middle of the twenty-first century, to values of $\mathrm{CO}_{2}$ not seen since the early Eocene (50 million years ago). If $\mathrm{CO}_{2}$ continues to rise further into the twenty-third century, then the associated large increase in radiative forcing, and how the Earth system would respond, would likely be without geological precedent in the last half a billion years.

\footnotetext{
${ }^{1}$ Ocean and Earth Science, National Oceanography Centre Southampton, University of Southampton, Southampton SO14 $3 Z$ H, UK. ${ }^{2}$ Department of Earth and Environmental Sciences, Wesleyan University, Middletown, Connecticut 06459, USA. ${ }^{3}$ School of Geographical Sciences and Cabot Institute, University of Bristol, University Road, Bristol BS8 1SS, UK. Correspondence and requests for materials should be addressed to G.L.F.

(email: Gavin.Foster@noc.soton.ac.uk).
} 
$\mathrm{T}$ he primary source of energy in the Earth's climate system is incoming solar radiation, termed total solar irradiance, or TSI. At equilibrium, because of the requirement of energy conservation, the Earth's radiative budget must balance such that TSI is equal to outgoing longwave radiation at the top of the atmosphere (a state known as radiative equilibrium). Since the radiation emitted by a body is a function of surface temperature, the Earth's 'effective temperature' $\left(T_{\mathrm{E}}\right)$ is the temperature at which radiative equilibrium is achieved assuming the Earth acts like a blackbody, and can be calculated (in K) using the following expression:

$$
T_{\mathrm{E}}=\left[\frac{F_{\mathrm{s}}(1-A)}{4 \sigma}\right]^{1 / 4}=256 \mathrm{~K}
$$

where $F_{\mathrm{s}}$ is the TSI (currently $\sim 1,368 \mathrm{Wm}^{-2}$ ), $\sigma$ is the StefanBoltzmann constant $\left(5.67 \times 10^{-8} \mathrm{~W} \mathrm{~m}^{-2} \mathrm{~K}^{-4}\right), A=0.29$ (ref. 1) is the Earth's average planetary albedo (the fraction of incoming radiation scattered or reflected back out of the atmosphere by clouds, particulates in the atmosphere and the Earth's surface), and the factor of 4 accounts for the spherical and rotating nature of the Earth. The $31 \mathrm{~K}$ difference between $T_{\mathrm{E}}$ and the observed surface temperature of the Earth $\left(+14.0^{\circ} \mathrm{C}\right.$ or $287.1 \mathrm{~K}$ is the 1961-1990 mean ${ }^{2}$ ) is almost entirely due to the action of the greenhouse effect (for example, ref. 3).

The majority $(\sim 75 \%)$ of the greenhouse effect is due to the warming effects of water vapour and clouds, with the noncondensing greenhouse gasses (predominantly $\mathrm{CO}_{2}$ and $\mathrm{CH}_{4}$ ) accounting for the remaining $25 \%$ (ref. 3). However, at the temperatures and pressures typical of the Earth's surface, water vapour and clouds act as feedbacks rather than drivers of the greenhouse effect, with $\mathrm{CO}_{2}$ and $\mathrm{CH}_{4}$, and the other noncondensing GHGs (for example, $\mathrm{N}_{2} \mathrm{O}$ ) determining the overall strength of the greenhouse effect ${ }^{3}$. Given this understanding, and that summarized in equation (1), the climatic evolution of the Earth over geological time is largely a function of the concentration of the non-condensing greenhouse gases, planetary albedo $(\mathrm{A})$ and the TSI $\left(F_{\mathrm{s}}\right.$; for example, ref. 4$)$.

Owing to the way the Sun generates energy though the nuclear fusion of hydrogen into helium, over time its luminosity has increased ${ }^{5}$. This is a relatively well-understood process and the TSI at any time $\left(F_{\mathrm{s}}^{\mathrm{t}}\right)$ can be approximated by the following function ${ }^{5}$ :

$$
F_{\mathrm{s}}^{t}=\frac{1}{1+\frac{2}{5}\left(1-\frac{t}{t_{0}}\right)} \times F_{\mathrm{s}}
$$

where $F_{\mathrm{s}}$ is the present day TSI $\left(1,368 \mathrm{Wm}^{-2}\right), t$ is the time of interest since the formation of the Earth (Myrs) and $t_{0}$ is the age of the Earth (4,567 Myrs (ref. 6), although here following ref. 5 we use a $t_{0}=4,700 \mathrm{Myrs}$ ). As a result, there has been an increase in TSI of $\sim 400 \mathrm{Wm}^{-2}$ since the formation of the Earth. The following equation relates this change in TSI relative to today to radiative forcing $\left(\Delta \mathrm{F}_{\text {sol }}\right)$ assuming a constant planetary albedo $(A)$ through time:

$$
\Delta F_{\mathrm{sol}}=\frac{\left(F_{\mathrm{s}}^{\mathrm{t}}-F_{\mathrm{s}}\right) \times(1-A)}{4} \mathrm{Wm}^{-2}
$$

The global mean surface temperature change $(\Delta T$, in $\mathrm{K})$ for a given change in radiative forcing $\left(\Delta F\right.$, in $\left.\mathrm{Wm}^{-2}\right)$ can be described by:

$$
\Delta T=\Delta F \times S
$$

Where $\mathrm{S}$ is the sensitivity parameter ${ }^{7}$, in $\mathrm{KW}^{-1} \mathrm{~m}^{2}$. Following ref. 4 , and assuming an effective emissivity, $\epsilon$, of the Earth of 0.6 (that is, $40 \%$ of longwave radiation is absorbed by greenhouse gases in the atmosphere), equation (1) can be used to define the following equation that describes $S$ for today's climate (where the surface temperature $=287.1 \mathrm{~K}$ ) in the absence of any climate feedbacks (for example, water vapour, sea-ice etc.), also known as the Planck response (hence the subscript ' $\left.\mathrm{P}^{\prime}\right)^{8}$ :

$$
\frac{\Delta T}{\Delta F}=S_{\mathrm{P}}=\frac{1}{4 \varepsilon \sigma T^{3}}=0.31 \mathrm{~K} \mathrm{~W}^{-1} \mathrm{~m}^{2}
$$

$S_{\mathrm{P}}$ depends on the overall strength of the greenhouse effect and the surface temperature of the Earth, and so this value is not necessarily applicable throughout Earth's history; nonetheless, this treatment provides a first-order constraint that the long-term secular increase in TSI of $400 \mathrm{Wm}^{-2}$ would be associated with a secular warming of at least $\sim 20 \mathrm{~K}$ over the last 4.5 billion years, if albedo and emissivity remained constant. Since the combined effect of the greenhouse gas and other climate feedbacks (for example, water vapour, lapse rate, sea-ice etc.) is positive ${ }^{8}$, this is a minimum estimate of $S$ and when all climate feedbacks are considered, $S_{\mathrm{a}}$ (where 'a' denotes actuo after ref. 7) is likely in the range of $0.8-1.6 \mathrm{~K} \mathrm{~W}^{-1} \mathrm{~m}^{2}$ (for example, refs $7,9-11$ ).

The actual evolution of Earth's temperature through geological time is a subject of considerable debate (for example, ref. 12), yet there is a longstanding view that, despite the increase in solar output, Earth's surface temperature was, for much of geological time, warmer, not colder, than today (for example, refs 13,14). This apparent inconsistency is known as the 'Faint Young Sun' paradox and to reconcile the observation of a relatively stable climate in the face of increasing solar output through time requires a parallel change in some other factors that influence Earth's radiative budget. First and foremost among these factors is thought to be a concomitant reduction in the strength of the greenhouse effect, and in atmospheric $\mathrm{CO}_{2}$ concentration in particular (for example, refs 15,16). The radiative forcing from changing $\mathrm{CO}_{2}$ can be estimated using the following formulation ${ }^{17}$ :

$$
\Delta F_{\mathrm{CO}_{2}}=5.32 \ln \left(\mathrm{C} / \mathrm{C}_{0}\right)+0.39 \ln \left(\mathrm{C} / \mathrm{C}_{0}\right)^{2}
$$

where $\Delta F_{\mathrm{CO}_{2}}$ is the radiative forcing from $\mathrm{CO}_{2}$ change (in $\mathrm{Wm}^{-2}$ ), $\mathrm{C}$ represents the concentration of $\mathrm{CO}_{2}$ at the time of interest and $C_{0}$ is the pre-industrial concentration of $\mathrm{CO}_{2}=278$ p.p.m. For the decrease in atmospheric $\mathrm{CO}_{2}$ to balance the increase in solar output over time, the following equation is required to be true (or at least approximately so):

$$
\Delta F_{\text {sol }}+\Delta F_{\mathrm{CO}_{2}} \approx 0 \mathrm{Wm}^{2}
$$

In this formulation we are ignoring the other non-condensing greenhouse gases (for example, $\mathrm{CH}_{4}, \mathrm{~N}_{2} \mathrm{O}$ ). This is partly out of practical necessity since there are currently no proxies for these gases, but is justifiable to a first order because variations in $\mathrm{CO}_{2}$ accounted for $\sim 80 \%$ of the greenhouse gas forcing on glacialinterglacial timescales ${ }^{4}$ and $\mathrm{CO}_{2}$ was likely the dominant greenhouse gas for the past 500 Myrs (refs 18-20).

Testing whether the apparent stability of surface temperature is a consequence of the relative stability of climate forcing, therefore, requires high-density, high-quality data on past atmospheric $\mathrm{CO}_{2}$ levels. Consequently, in this study we compile the available $\mathrm{CO}_{2}$ data for the last $420 \mathrm{Myrs}$ where, although the magnitude in the change of solar output is reduced relative to changes on longer timescales, data availability is sufficient to provide a detailed picture of the evolution of atmospheric $\mathrm{CO}_{2}$. The relative stability of climate over this interval is constrained by three lines of evidence: (i) the continued presence of complex life, given the thermal limits of metazoans $\left(<40-50^{\circ} \mathrm{C}\right.$; ref. 21$)$ and despite a number of mass extinctions ${ }^{22}$; (ii) the continuous presence of liquid water and the occurrence of climate-sensitive sedimentary deposits (for example, coal versus glacial deposits) that indicate warm and cold periods but no evidence of an overall 
long-term secular trend (Fig. 1) ${ }^{23}$; and (iii) moderate tropical sea surface temperatures $\left(25-40^{\circ} \mathrm{C}\right)$ as recorded by oxygen and clumped isotope analysis of fossil marine carbonates ${ }^{24-27}$. Our new compilation shows that this climate stability was the result of a long-term decline in atmospheric $\mathrm{CO}_{2}$ that, in terms of radiative forcing, approximately cancelled out the increase in solar output. This long-term view of climate forcing provides a valuable geological context for potential levels of $\mathrm{CO}_{2}$ in our warming future.

\section{Results}

A new $\mathrm{CO}_{2}$ compilation. In order to better understand the role of the greenhouse effect in Earth's climate evolution, we have compiled $\sim 1,500$ discrete estimates of atmospheric $\mathrm{CO}_{2}$ from five independent techniques drawn from 112 published studies covering the last 420 Myrs (Supplementary Data 1). We uniformly apply a set of criteria and the latest understanding, described in the supplement, to screen the available $\mathrm{CO}_{2}$ records. By following these criteria, the ages and $\mathrm{CO}_{2}$ values associated with some records are revised (see Methods), and $\sim 1 / 5$ of the published estimates have been excluded (leaving $n=1,241$ in our final compilation). This standardization process helps ensure the highest-quality compilation whose individual records can be more cleanly compared to one another.

Our new compilation is shown in Fig. 1 and, compared to older compilations, there is better agreement between the different methods of $\mathrm{CO}_{2}$ reconstruction ${ }^{28}$. In this case, this is largely due to the refinement of the pedogenic carbonate proxy following ref. 29 (see Methods). However, despite our efforts to improve the compilation, there are still relatively large uncertainties at times and disagreements remain between techniques for some time intervals (Fig. 1). It is also apparent that the early parts of the record rely on fewer observations and are characterized by a reduced diversity in proxy type (Supplementary Fig. 1). In order to gain a better appreciation of the multi-million-year evolution of $\mathrm{CO}_{2}$, and in light of these uncertainties and limitations we have followed a probabilistic approach where Monte Carlo resampling is used to generate 1,000 artificial time series of $\mathrm{CO}_{2}$ with each data point randomly perturbed within its age $(X)$ and $\mathrm{CO}_{2}(Y)$ uncertainty. Each realization was then interpolated to a regular $0.5 \mathrm{Myr}$ spacing and a LOESS fit was performed with the degree of smoothing optimized by generalized cross-validation ${ }^{30}$. At each time step the distribution of LOESS fits was evaluated and the maximum probability, hence the most likely value for long-term $\mathrm{CO}_{2}$, and the associated 68 and 95 percentile ranges were determined (Fig. 1 and Supplementary Data 2).

Our new compilation and probabilistic treatment reveals that for the last $\sim 420 \mathrm{Myrs}, \mathrm{CO}_{2}$, on the whole, has been elevated compared to pre-industrial values (278 p.p.m.). The highest $\mathrm{CO}_{2}$ values of $\sim 2,000$ p.p.m. were reached during the Devonian ( $\sim 400$ Myrs ago) and Triassic (220-200 Myrs ago), with individual estimates ranging up to a maximum of $\sim 3,700 \pm 1,600$ p.p.m. at $215 \mathrm{Myrs}$. In contrast, values close to pre-industrial are found during much of the Carboniferous ( $\sim 300 \mathrm{Myrs}$ ago) and late Cretaceous ( $\sim 80 \mathrm{Myrs}$ ago). A linear fit to either the entire $\mathrm{CO}_{2}$ compilation, or a resampling of our LOESS fit to reflect the original data density, reveals that long-term average $\mathrm{CO}_{2}$ has declined over the last 420 Myrs by 3.4 p.p.m. per Myrs (Fig. 1).

Radiative forcing through the last $\mathbf{4 2 0}$ million years. Radiative forcing from $\mathrm{CO}_{2}$ change can be calculated using equation (6). This can then be combined with the radiative forcing from the increase in solar output defined by equation (3) (Fig. 2a); the temporal evolution of the simple sum of these terms $\left(\Delta F_{\mathrm{CO} 2, \mathrm{sol}}\right)$ is shown in Fig. 2b. As has been noted elsewhere with prior Phanerozoic $\mathrm{CO}_{2}$ compilations (for example, refs 31,32 ), there is a good first-order agreement between $\mathrm{CO}_{2}$ levels and the occurrence of greenhouse/icehouse states (Fig. 1): $\mathrm{CO}_{2}$ is high during greenhouse climate states and low during icehouse climates. Our data support previous work suggesting that, when $\Delta F_{\mathrm{CO} 2 \text {,sol }}$ is considered, icehouse states generally occur when climate forcing drops below approximately $+1-2 \mathrm{Wm}^{-2}$ (refs 31,32). This treatment also reveals that for the last 420 Myrs, despite a gradual $4 \%$ increase in solar luminosity (equivalent to $+9 \mathrm{Wm}^{-2}$ of radiative forcing), there has been very little longterm change in $\Delta F_{\mathrm{CO} 2 \text {,sol }}$ (despite shorter-term fluctuations of up to $10 \mathrm{Wm}^{-2}$ ), with a linear fit to all the data suggesting only a slight decrease of $0.004 \mathrm{Wm}^{-2}$ per Myrs $( \pm 0.001$ 1 s.e.m.; $P=0.0003$; red line on Fig. 2b); a linear fit to our LOESS fit resampled with the original data density yields a slightly higher negative slope $(-0.008 \pm 0.001 \quad 1$ s.e.m.; $P<0.0001$; black line Fig. 2b). This indicates that the long-term decrease in $\mathrm{CO}_{2}$ over the last 420 Myrs has largely compensated for the increase in solar output over the interval. In terms of shorter-term radiative imbalances, $95 \%$ of the $\Delta F_{\mathrm{CO} 2 \text {,sol }}$ values are within $\pm 7 \mathrm{Wm}^{-2}$ and $68 \%$ within $+5 /-3 \mathrm{Wm}^{-2}$ (Fig. 3). Thus, even on multi-

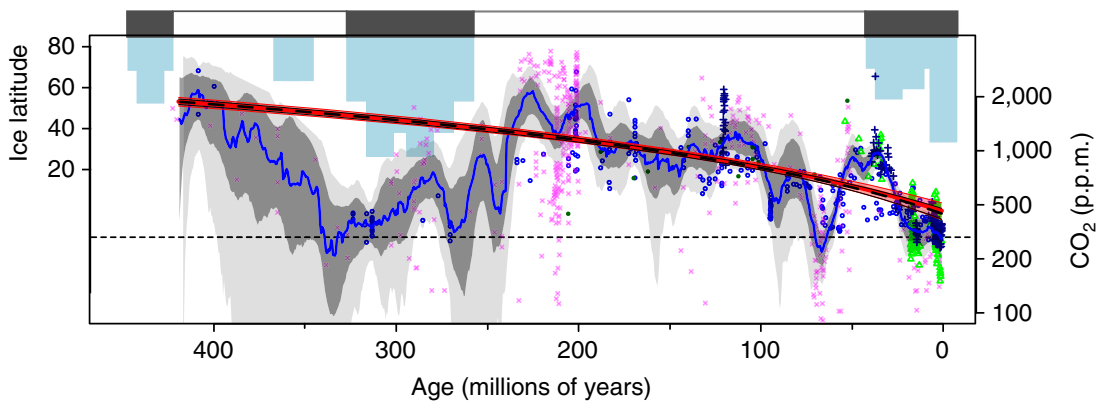

Figure 1 | Temporal evolution of climate and atmospheric $\mathbf{C O}_{\mathbf{2}}$. Latitudinal extent of continental ice deposits ${ }^{23}$ (blue bars) and multi-proxy atmospheric $\mathrm{CO}_{2}$ (in p.p.m.) compiled from the literature (data found in Supplementary Data 1; symbols). $\mathrm{CO}_{2}$ from leaf stomata shown in blue circles, pedogenic carbonate $\delta^{13} \mathrm{C}$ as pink crosses, boron isotopes in foraminifera as green triangles, liverwort $\delta^{13} \mathrm{C}$ as dark blue filled circles and $\delta^{13} \mathrm{C}$ of alkenones as dark blue crosses. The most likely LOESS fit through the data, taking into account X- and Y- uncertainty is shown as the blue line (data found in Supplementary Data 2). 68 and $95 \%$ confidence intervals are shown as dark and light grey bands. Red line is a linear best fit (curved due to log-scale for $y$ axis) and $95 \%$ confidence interval for least squares regression through the $\mathrm{CO}_{2}$ data $\left(m=3.4 \pm 0.171\right.$ s.e.m., $\left.R^{2}=0.26, P<0.0005\right)$. Black line is least squares fit through the LOESS best fit (blue line) resampled to original data density $\left(m=3.5 \pm 0.121\right.$ s.e.m., $\left.R^{2}=0.44, P<0.0005\right)$. Dashed line is pre-industrial $\mathrm{CO}_{2}$ (278 p.p.m.). Icehouse time intervals are indicated by a black band and greenhouse intervals by a white band. 


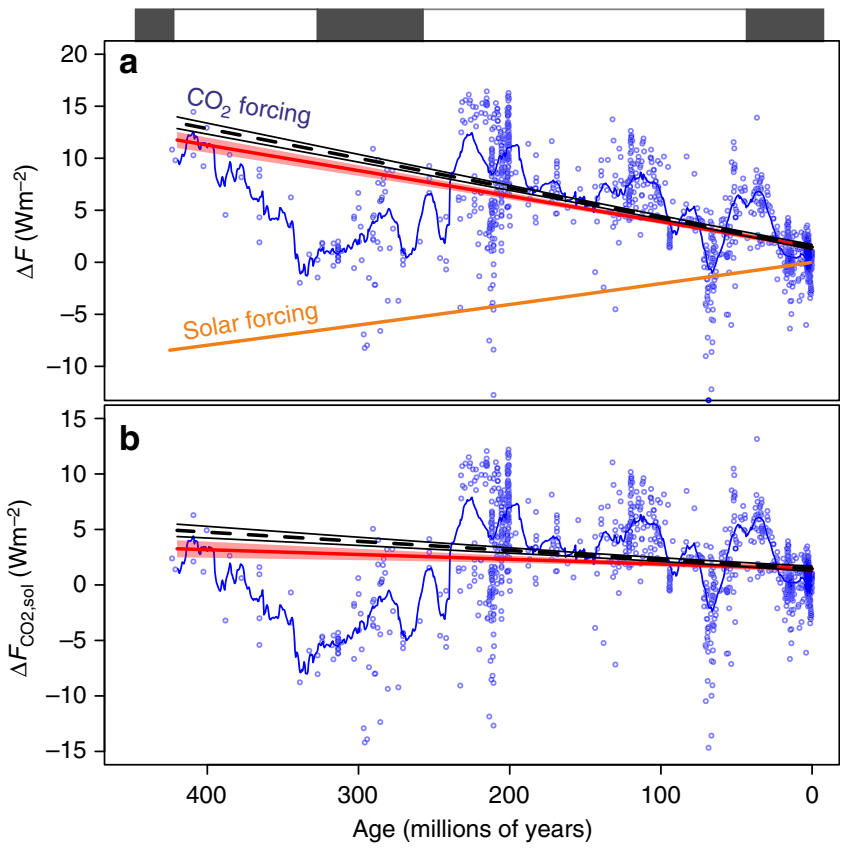

Figure 2 | Temporal evolution of climate forcing. (a) $\mathrm{CO}_{2}$ data (blue circles) and LOESS best fit (blue line; Supplementary Data 2) with $\Delta F$ for $\mathrm{CO}_{2}$ calculated as in equation (6). The change in solar forcing $\left(\Delta F_{\text {sol }}\right)$ calculated using equations ( 2 and 3 ). (b) $\Delta F_{\mathrm{CO} 2 \text {,sol }}$ for data (blue circles) and LOESS best fit (blue line). Red line is a linear best fit and $95 \%$ confidence interval for least squares regression through the $\Delta F_{\mathrm{CO} 2, \text { sol }}$ data (blue circles; $m=-0.004 \pm 0.0011$ s.e.m., $R^{2}=0.01, P=0.0003$ ). Black line is least squares fit through the LOESS best fit resampled to original data density (blue line; $m=0.008 \pm 0.0011$ s.e.m., $R^{2}=0.06, P<0.0001$ ). Icehouse time intervals are indicated by a black band and greenhouse intervals by a white band.

million-year timescales (and sometimes shorter) the external radiative forcing (not considering the action of additional feedbacks internal to the climate system such as the ice-albedo feedback) has not varied beyond $\pm 2.0 \%$ of the total incoming radiation $\left(\sim 340 \mathrm{Wm}^{-2}\right)$.

\section{Discussion}

The concentration of atmospheric $\mathrm{CO}_{2}$ on multi-million-year timescales depends largely on the balance between the input of $\mathrm{CO}_{2}$ from volcanism, metamorphism and organic carbon weathering and the output of $\mathrm{CO}_{2}$ from silicate weathering and organic carbon burial ${ }^{15}$. Since the magnitude of silicate weathering is climatically sensitive (that is, a function of temperature and precipitation; for example, ref. 33), silicate weathering also buffers the $\mathrm{CO}_{2}$ content of the atmosphere by acting as a negative feedback ${ }^{15}$. However, we note that in many modern settings silicate weathering is supply-limited ${ }^{33}$. Thus, for silicate weathering to operate as a climate feedback, the Earth must be sufficiently tectonically active to ensure an adequate supply of fresh minerals ${ }^{34}$.

The marked 'double-hump' pattern of the $\mathrm{CO}_{2}$ reconstruction (Fig. 1) that is also common to other compilations (for example, refs 28,35 ) is likely caused by changes in the inputs and outputs of $\mathrm{CO}_{2}$ in response to the supercontinent cycle ${ }^{36}$. For example, the low $\mathrm{CO}_{2}$ during the Carboniferous $(\sim 300 \mathrm{Myrs}$ ago $)$ and during the later parts of the Cenozoic (last 65 Myrs) was likely a result of a reduced volcanic flux and/or enhanced silicate weathering, at least in part due to higher continental relief during supercontinent construction phase. During the
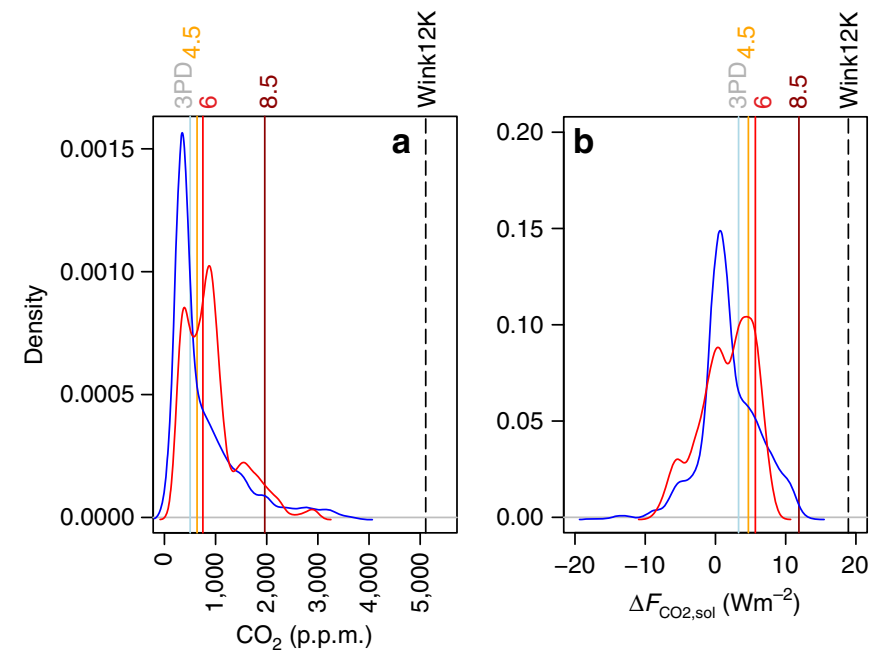

Figure 3 | Probability density functions of climate forcing.

(a) Atmospheric $\mathrm{CO}_{2}$ with proxy data in blue (Supplementary Data 1) and LOESS best fit (Supplementary Data 2) in red. Vertical lines show maximum atmospheric $\mathrm{CO}_{2}$ from relevant representative concentration pathways (RCP) (colours) ${ }^{39}$ and from a $12,000 \mathrm{Pg} C$ scenario (from ref. 41; Wink12K,

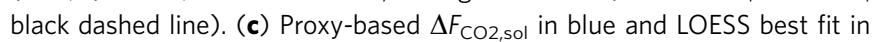
red along with relevant RCP scenarios (colours) ${ }^{39}$ and $12,000 \mathrm{Pg} C$ scenario (black dashed line) ${ }^{41}$.

intervening greenhouse intervals the reverse was likely true (high volcanic flux and/or low silicate weathering due to low relief) ${ }^{36,37}$. An additional factor in the decline in $\mathrm{CO}_{2}$ was the overall enhancement of silicate weathering due to the expansion of the terrestrial biosphere over the last 400 million years or so (refs 16,38). It is probably this expansion, along with the silicate weathering-negative feedback (facilitated by sufficiently active plate tectonic regime ${ }^{34}$ ), that was the key in keeping $\Delta F_{\mathrm{CO} \text {,Sol }}$ relatively constant over the long term (for example, ref. 16). Indeed, as with previous compilations ${ }^{35}$, our new $\mathrm{CO}_{2}$ record largely agrees with the GEOCARB carbon cycle model that incorporates these long-term changes in silicate weathering (Supplementary Fig. 2), especially when the uncertainties in both records are considered ${ }^{35}$. This serves to further underscore the importance of the rise of the terrestrial biosphere, along with plate tectonics and silicate weathering, in ensuring climate stability through time ${ }^{16}$ and provides additional support for our broad understanding of the Earth's long-term carbon cycle as encapsulated by the GEOCARB model ${ }^{35,38}$ (Supplementary Fig. 2).

Regardless of the ultimate cause for the observed relative stability in $\Delta F_{\mathrm{CO} 2 \text {,sol }}$ over the last 420 million years, business-asusual emission scenarios (for example, representative concentration pathway RCP8.5) ${ }^{39}$ for fossil fuel emissions suggest that atmospheric $\mathrm{CO}_{2}$ could peak in 2,250 $\mathrm{AD}$ at $\sim 2,000$ p.p.m. $\mathrm{CO}_{2}$ values as high as this were last seen in the Triassic around 220-200 Myrs ago (Figs 3 and 4). However, because of the steady increase in solar output over time, in terms of radiative forcing by the end of this century RCP8.5 is similar to the early Eocene, and by $2,250 \mathrm{AD}$ exceeds what is recorded in the geological record for at least $99.9 \%$ of the last 420 Myrs (Figs 3 and 4). A recent study suggested that if both conventional and non-conventional fossil fuel reserves (amounting to $\sim 12,000 \mathrm{PgC}$; ref. 40 ) were exhausted in such a business-as-usual scenario, atmospheric $\mathrm{CO}_{2}$ could rise to $\sim 5,000$ p.p.m. by $2,400 \mathrm{AD}$ (refs 41,42 ), which is clearly higher, in terms of both forcing and absolute $\mathrm{CO}_{2}$, than at any time captured by our compilation (Figs 3 and 4, Wink12K scenario). Such a scenario therefore risks subjecting the Earth to a 


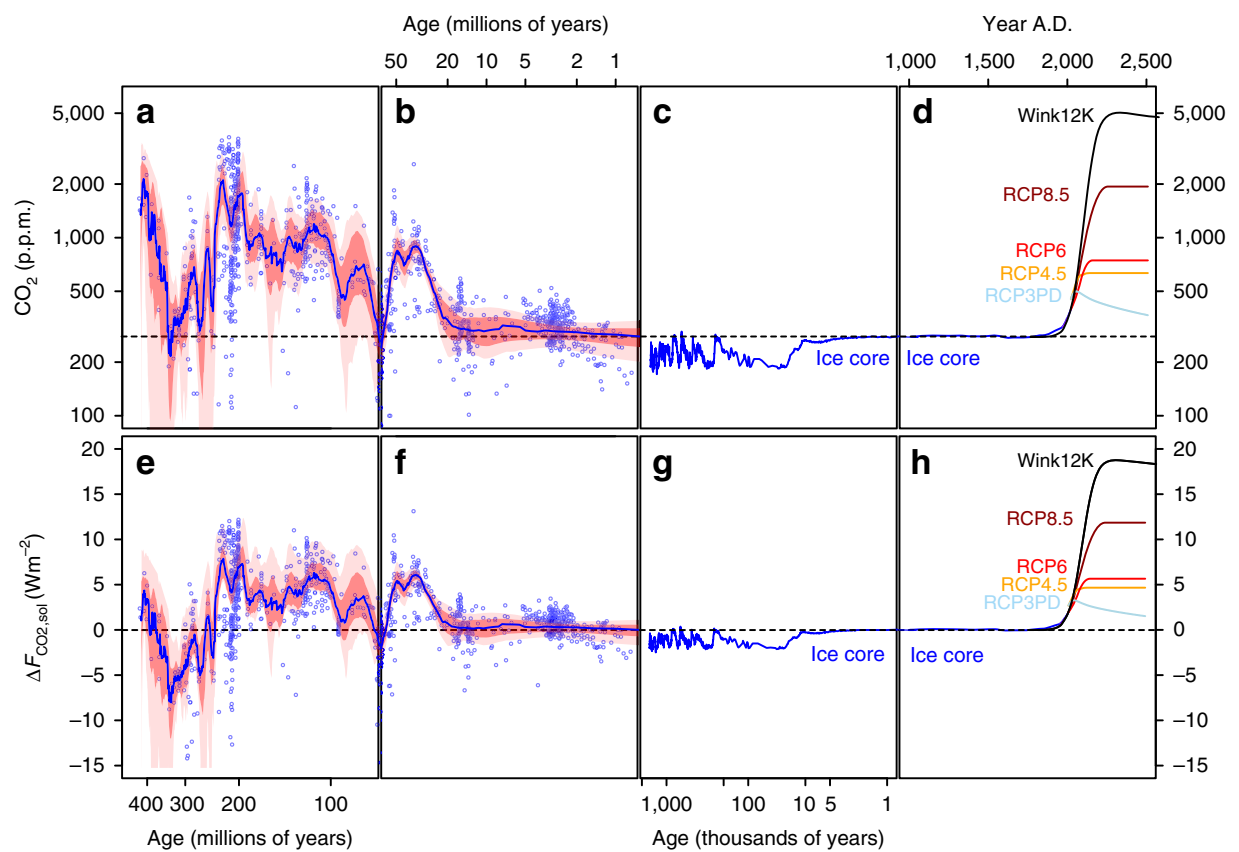

Figure 4 | Temporal evolution of $\mathbf{C O}_{\mathbf{2}}$ and climate forcing. (a,b) Proxy-based atmospheric $\mathrm{CO}_{2}$ (Supplementary Data 1) on a log timescale with best fit LOESS and associated uncertainty envelope (Supplementary Data 2). (c) Ice core atmospheric $\mathrm{CO}_{2}$ from ref. 82 on log timescale. (d) Atmospheric $\mathrm{CO}_{2}$ on line timescale from ice core and observation record ${ }^{82}$ and future RCP ${ }^{8}$ and other ${ }^{41}$ scenarios (RCP3PD-grey, RCP4.5-orange, RCP6-red,

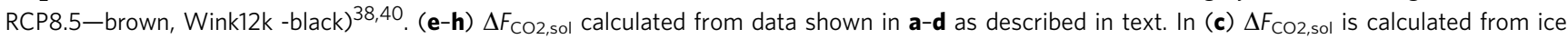
core $\mathrm{CO}_{2}$ estimates assuming no change in solar output ${ }^{82}$. No change in solar output is also applied to the records in $\mathbf{h}$.

climate forcing that has no apparent geological precedent, for at least the last 420 Myrs. We should be aware of course of the limitations of the geological record, and it is debatable whether an extreme climate change event analogous to the Anthropocene, if it existed at all, would leave a detectable signal, given our current $\mathrm{CO}_{2}$ proxies and records ${ }^{43}$. Nonetheless, prolonged warm greenhouse climate states have occurred in the past, but the rates of climate change in the geological record are on the whole very likely slower than what we are currently experiencing (for example, ref. 44). Unabated fossil fuel use therefore has the potential to push the climate system into a state that has not been seen on Earth in at least the last 420 Myrs.

\section{Methods}

Assembling the $\mathrm{CO}_{2}$ compilation. The new $\mathrm{CO}_{2}$ compilation here consists of 1,241 independent estimates coming from five proxy methods and 112 published studies. In putting this compilation together, we applied a uniform set of criteria described next to screen potential $\mathrm{CO}_{2}$ records. By following these criteria, the $\mathrm{CO}_{2}$ values associated with some records are revised, while other records are excluded all together. This standardization process helps ensure a high-quality compilation whose individual records can be more cleanly compared to one another. Of course, some of our criteria may be judged at some point to be incorrect. It is in this light, and in the spirit of full transparency, that we describe our criteria. We consider our compilation to be a 'living document', not only because in the future new records will be added but because existing records will be interpreted in new ways. The compilation can be found in Supplementary Data 1.

First, we excluded all goethite-based $\mathrm{CO}_{2}$ estimates ${ }^{45-48}$ due to uncertainties in modelling some of the isotopic fractionation factors ${ }^{49}$. We also excluded all $\mathrm{B} / \mathrm{Ca}-$ based estimates ${ }^{50}$ because the environmental controls on $\mathrm{B} / \mathrm{Ca}$ are currently not well understood ${ }^{51}$. The nahcolite proxy is based on well-described mineral phase equilibria $^{52}$, but we exclude the published estimates because it is not possible to assign mean values (all values within a defined $\mathrm{CO}_{2}$ interval are equally probable). It is important to note, however, that the range described by these nahcolite estimates agree well with the other data in our compilation. We do not include the boron-based estimates of Pearson and Palmer ${ }^{53}$ owing to problems related to potential diagenesis, potential analytical issues, vital effects of extinct species and the evolution of seawater $\delta^{11} \mathrm{~B}$ and alkalinity (as discussed in ref. 19). For the alkenone-based records of Pagani and colleagues ${ }^{54-58}$, we adopt the compilation of ref. 58 who imposed a uniform set of quality controls on the original data sets and used a TEX ${ }_{86}$ temperature record (versus the $\delta^{18} \mathrm{O}$ of ref. 54 ). We update all Cenozoic liverwort-based estimates ${ }^{59}$ with the atmospheric $\delta^{13} \mathrm{C}$ model of ref. 60 .

For estimates calculated from stomatal ratios ( $\mathrm{SR}$, where $\mathrm{SR}=$ ratio of stomatal frequency in nearest living equivalent to fossil), two transfer functions to $\mathrm{CO}_{2}$ have been proposed: $1 \mathrm{SR}=1 \mathrm{RCO}_{2}$ and $1 \mathrm{SR}=2 \mathrm{RCO}_{2}$, where $\mathrm{RCO}_{2}=$ ratio of atmospheric $\mathrm{CO}_{2}$ in the past to pre-industrial conditions (300 p.p.m.; refs 61,62). Following Beerling and Royer ${ }^{63}$, we use these two functions to establish the uncertainty bounds in estimated $\mathrm{CO}_{2}$. Owing to the ad hoc nature of these functions, $\mathrm{CO}_{2}$ estimates from stomatal ratios should be considered semiquantitative only. We modify many of the stomatal-based estimates of Retallack $^{64}$. First, we only use estimates associated with five or more cuticle fragments, as this is the minimum sampling required in most cases for robust estimates ${ }^{65}$. We use the quantitative transfer function of $\operatorname{Royer}^{65}$ for estimates coming from Ginkgo adiantoides, the fossil species considered conspecific with extant G. biloba ${ }^{66}$. For estimates coming from other species within the Ginkgo genus we use the stomatal ratio approach, and we exclude estimates not coming from Ginkgo as these other groups are too distantly related to Ginkgo and have not been calibrated correctly ${ }^{67}$.

A recent development that we have incorporated is the lowering of $\mathrm{CO}_{2}$ estimates from the pedogenic carbonate method ${ }^{29}$. This is because one of the key input parameters, the concentration of biologically derived $\mathrm{CO}_{2}$ in the soil $(S(\mathrm{z}))$, had been overestimated in most paleosols by a factor of two or more ${ }^{29,68}$. Here we adjust most $\mathrm{CO}_{2}$ estimates assuming a $S(\mathrm{z})$ of 2,000 p.p.m. (ref. 68). This is a simple correction that masks variability in $S(z)^{69}$, but it is nonetheless a useful place to start and in most cases represents an improvement over previous estimates ${ }^{70}$. This is an area where we anticipate substantial revision in the near future. Along these lines, several proxies for $S(z)$ have been proposed ${ }^{69-76}$, and we use estimates of $S(z)$ derived from these methods when available. We also replace some of the pedogenic carbonate-based estimates of ref. 73 with those based on the same sediments ${ }^{74,75}$ because these newer studies provide better constraints on organic matter $\delta^{13} \mathrm{C}$. Lastly, we collapse the high-resolution stomatal-based record of ref. 76 into one estimate calculated from the mean of the individual estimates.

Uncertainties in paleo- $\mathrm{CO}_{2}$ estimates have been assessed in different ways. Most earlier uncertainties associated with the pedogenic carbonate method, for example, only incorporate uncertainty in $S(\mathrm{z})$; potential uncertainties in other input variables are ignored. In addition, errors associated with stomatal-based methods that involve quantitative regression equations usually only reflect uncertainty in the regressions; uncertainties in the fossil measurements are ignored. This means that error bars can convey different meanings, which hinders comparisons across methods. In recent years, Monte Carlo simulations for propagating uncertainty in multiple input variables have been developed for all five proxy systems ${ }^{11,55,59,77}$. So long as the reported percentile ranges are identical, these simulations facilitate better cross-method comparisons. 
We attempt here to standardize reported uncertainties so that they incorporate uncertainty in all input variables; we also standardize the percentile levels (16 and 84 ; equivalent to \pm 1 s.d. for a normally distributed population). For uncertainties derived from Monte Carlo simulations that propagate uncertainties in most or all input variables (this covers most estimates from the alkenone, boron and liverwort proxies, as well as most recent estimates from pedogenic carbonates and stomata), we adjust if needed to the 16 and 84 percentile levels: for example, if the 2.5 and 97.5 percentiles are reported, we assume the population has a normal distribution and cut the uncertainties in half. Because most paleo- $\mathrm{CO}_{2}$ estimates have a rightskewed distribution, this means that we are overestimating the magnitude of the upper uncertainty and underestimating the magnitude of the lower uncertainty. For uncertainties with the pedogenic carbonate method derived by varying only $S(\mathrm{z})$, we adopt for the 16 and 84 percentiles the generic recommendation of $+100 \% /-50 \%$ of the median value calculated from multifactorial Monte Carlo simulations ${ }^{78}$; these uncertainties are larger and probably more representative than the reported uncertainties. Similarly, for stomatal estimates whose uncertainties only take into account variance in the transfer function, we assume 16 and 84 percentiles equal to $+100 \% /-40 \%$ of the median value, a range that takes into account representative uncertainty in both the transfer function and the fossil measurement $\mathrm{s}^{77}$

All ages have been updated to the 2012 Geologic Time Scale ${ }^{79}$. Many $\mathrm{CO}_{2}$ estimates from terrestrial proxies have biostratigraphic (for example, 'Maastrichtian'), magnetostratigraphic or chronostratigraphic constraints. For records with biostratigraphic or magnetostratigraphic constraints, we update their ages following the new Time Scale. Many $\mathrm{CO}_{2}$ estimates have no reported age uncertainties. In almost all cases, these estimates have excellent age control, the most common example being estimates from marine sediment cores (for example, all boron- and alkenone-based estimates). Some terrestrial-based data fall under this category too, for example, the Triassic-Jurassic sediments in the Newark Supergroup ${ }^{80}$. When no age uncertainty is reported we take the 1 s.d. to be $0.001 \mathrm{Myr}$ for marine records and $4 \%$ for terrestrial records.

Monte Carlo sampling and LOESS fitting. Monte Carlo approach was used to generate 1,000 realizations of the multiproxy $\mathrm{CO}_{2}$ time series with each data point randomly perturbed within its age and $\mathrm{CO}_{2}$ uncertainty as given in Supplementary Data 1. For $\mathrm{CO}_{2}$ estimates with asymmetric uncertainties, we force symmetry by assuming \pm 1 s.d. is equal to the average offset between the median and the 16 and 84 percentiles. Each realization of the time series was then interpolated to a regular $0.5 \mathrm{Myr}$ spacing and LOESS curves were fitted to each interpolated realization using the programme $\mathrm{R}^{81}$. The optimal degree of smoothing was determined for each interpolated realization using generalized cross-validation ${ }^{30}$. At each $0.5 \mathrm{Myr}$ time step the distribution of LOESS curves was evaluated and the probability distribution was determined. From this probability distribution the most likely value (or probability maximum) and the upper and lower limits corresponding to 68 and $95 \%$ confidence limits were identified. These variables are given in Supplementary Data 2.

Owing to the nature of the proxies used the make-up and coverage of our new $\mathrm{CO}_{2}$ compilation varies considerably as a function of time. By grouping the data into 2.5 million year bins, Supplementary Fig. 1 shows that the number of observations in each 2.5 million year bin generally increases towards the present, with a notable exception of a peak at $\sim 200$ million years ago at the TriassicJurassic boundary. Supplementary Fig. 1 also shows that the boron isotope and alkenone $\delta^{13} \mathrm{C}$ methods are restricted to the Cenozoic and liverwort $\delta^{13} \mathrm{C}$ proxy are concentrated in the middle part of the last 420 million years. Estimates based on fossil plant stomata appear focused in the last 200 million years, with only sporadic coverage over the early part of the interval. Only $\mathrm{CO}_{2}$ estimates from pedogenic carbonate $\delta^{13} \mathrm{C}$ method are relatively evenly spread across the last 420 million years. To examine the influence of this uneven distribution of proxy types we performed the LOESS fitting a further two times but without one of the dominant proxy systems (no-pedogenic carbonate, no-stomata), these alternatives are shown with the complete data set in Supplementary Fig. 3. While subtle variations exist, overall the large-scale structure remains intact, although if the pedogenic carbonate estimates are discarded the early part of the Phanerozoic is largely under sampled. In terms of long-term $\mathrm{CO}_{2}$ change, however, discarding all the estimates from either the pedogenic carbonate method or the stomatal method does not change our principal conclusions. For instance, the long-term $\mathrm{CO}_{2}$ decline over the last 420 million years without the pedogenic carbonates is 2 p.p.m. per million years, and without the estimates from the plant stomata method it is 4 p.p.m. per million years. Both of which are similar to the $\mathrm{CO}_{2}$ decline we determine for the complete data set (3.4 p.p.m. per million years), indicating that a long-term decline in $\mathrm{CO}_{2}$ over the last 420 million years is a robust observation. In terms of $\Delta F_{\mathrm{CO} 2, \text { sol }}$ the long-term trends are also similar being $0.008 \pm 0.001 \mathrm{Wm}^{-2}\left(R^{2}=0.03\right.$ and $P<0.001)$ and $0.0001 \pm 0.001 \mathrm{Wm}^{-2}\left(R^{2}=<0.001, P=0.94\right)$ for no-stomata and no-pedogenic carbonate, respectively.

Data availability. The authors declare that all data supporting the findings of this study are available within the Supplementary Information files associated with this manuscript.

\section{References}

1. Stephens, G. L. et al. The albedo of Earth. Rev. Geophys 53, 141-163 (2015).

2. Jones, P. D., New, M., Parker, D. E., Martin, S. \& Rigor, I. G. Surface air temperature and its changes over the past 150 years. Rev Geophys 37, 173-199 (1999).

3. Lacis, A. A., Schmidt, G. A., Rind, D. \& Ruedy, R. A. Atmospheric $\mathrm{CO}_{2}$ : principal control knob governing Earth's temperature. Science 330, 356-359 (2010).

4. Kohler, P. et al. What caused Earth's temperature variations during the last 800,000 years? Data-based evidence on radiative forcing and constraints on climate sensitivity. Quart. Sci. Rev. 29, 129-145 (2010).

5. Gough, D. O. Solar interior structure and luminosity variations. Solar Phys. 74, 21-34 (1981).

6. Connelly, J. N. et al. The absolute chronology and thermal processing of solids in the solar protoplanetary disk. Science 338, 651-655 (2012).

7. Rohling, E. J. et al. Making sense of palaeoclimate sensitivity. Nature 491, 683-691 (2012).

8. Roe, G. Feedbacks timescales, and seeing red. Annu. Rev. Earth Planet. Sci. 37, 93-115 (2009).

9. Hansen, J. et al. Target atmospheric $\mathrm{CO}_{2}$ : where should humanity aim? Open Atmos. Sci. J. 2, 217-231 (2008).

10. Royer, D. L., Berner, R. A. \& Park, J. Climate sensitivity constrained by $\mathrm{CO}_{2}$ concentrations over the past 420 million years. Nature 446, 530-532 (2007).

11. Martínez-Botí, M. A. et al. Plio-Pleistocene climate sensitivity evaluated using high-resolution $\mathrm{CO}_{2}$ records. Nature 518, 49-54 (2015).

12. Grossman, E. L. in Reconstructing Earth's Deep-time Climate: The State of the Art in 2012: Presented as a Paleontological Society Short Course at the Annual Meeting of the Geological Society of America, Charlotte, North Carolina, November 3, 2012, Vol. 18 (eds Ivany, L. C. \& Huber, B. T.) 39-67 (The Paleontological Society, 2012).

13. Hren, M. T., Tice, M. M. \& Chamberlain, C. P. Oxygen and hydrogen isotope evidence for a temperate climate 3.42 billion years ago. Nature 462, 205-208 (2009).

14. Blake, R. E., Chang, S. J. \& Lepland, A. Phosphate oxygen isotope evidence for temperate and biologically active Archaean ocean. Nature 464, 1029-1032 (2010).

15. Walker, J. C. G., Hays, P. B. \& Kastings, J. F. A negative feedback mechanism for the long-lasting stablization of the Earth's surface temperature. J. Geophys. Res. 86, 9776-9782 (1981).

16. Schwartzman, D. W. \& Volk, T. Biotic enhancement of weathering and the habitability of Earth. Nature 340, 457-459 (1989).

17. Byrne, B. \& Goldblatt, C. Radiative forcing at high concentrations of well-mixed greenhouse gases. Geophys. Res. Lett. 41, 152-160 (2013).

18. Beerling, D. J., Fox, A., Stevenson, D. S. \& Valdes, P. J. Enhanced chemistryclimate feedbacks in past greenhouse worlds. Proc. Natl Acad. Sci. USA 108, 9770-9775 (2011).

19. Anagnostou, E. et al. Changing atmospheric $\mathrm{CO}_{2}$ concentration was the primary driver of early Cenozoic climate. Nature 533, 380-384 (2016).

20. Bartdorff, O., Wallmann, K., Latif, M. \& Semenov, V. Phanerozoic evolution of atmospheric methane. Global Biogeochem. Cycles 22, GB1008 (2008).

21. Nguyen, K. D. T. et al. Upper temperature limits of tropical marine ectotherms: global warming implications. PLoS ONE 6, e29340 (2011).

22. Raup, D. M. \& Sepkoski, Jr J. J. Periodicity of extinctions in the geologic past. Proc. Natl Acad. Sci. USA 81, 801-805 (1984).

23. Crowley, T. J. in Tectonic Boundary Conditions for Climatic Reconstructions (eds Crowley, J. L. \& Burke, K.) 3-17 (Oxford University Press, 1998).

24. Came, R. E. et al. Coupling of surface temperatures and atmospheric $\mathrm{CO}_{2}$ concentrations during the Palaeozoic era. Nature 449, 198-201 (2007).

25. Gothmann, A. M. et al. Fossil corals as an archive of secular variations in seawater chemistry since the Mesozoic. Geochim. Cosmochim. Acta 160, 188-208 (2015).

26. Cummins, R. C., Finnegan, S., Fike, D. A., Eiler, J. M. \& Fischer, W. W. Carbonate clumped isotope constraints on Silurian ocean temperature and seawater $\delta^{18}$ O. Geochim. Cosmochim. Acta 140, 241-258 (2014).

27. Veizer, J. \& Prokoph, A. Temperatures and oxygen isotopic composition of the Phanerzoic oceans. Earth-Sci. Rev. 146, 92-104 (2015).

28. Royer, D. L. et al. $\mathrm{CO}_{2}$ as a primary driver of Phanerozoic climate. GSA Today 14, 4-10 (2004).

29. Breecker, D. O., Sharp, Z. D. \& McFadden, L. D. Atmospheric $\mathrm{CO}_{2}$ concentrations during ancient greenhouse climates were similar to those predicted for A.D. 2100. Proc. Natl Acad. Sci. USA 107, 576-580 (2010).

30. Chandler, R. \& Scott, M. Statistical Methods for Trend Detection and Analysis in the Environmental Sciences (Wiley, 2011).

31. Crowley, T. J. \& Berner, R. A. $\mathrm{CO}_{2}$ and climate change. Science 292, 870-872 (2001). 
32. Royer, D. L. $\mathrm{CO}_{2}$-forced climate thresholds during the Phanerozoic. Geochim. Cosmochim. Acta 70, 5665-5675 (2006).

33. West, A. J., Galy, A. \& Bickle, M. Tectonic and climatic controls on silicate weathering. Earth Planet. Sci. Lett. 235, 211-228 (2005).

34. Foley, B. J. The role of plate tectonic-climate coupling and exposed land area in the development of habitable climates on rocky planets. Astrophys. J. 812, 1-23 (2015).

35. Royer, D. L. et al. Error analysis of $\mathrm{CO}_{2}$ and $\mathrm{O}_{2}$ estimates from the long-term geochemical model GEOCARBSULF. Am. J. Sci. 314, 1259-1283 (2014).

36. Berner, R. A. \& Kothavala, Z. GEOCARB III: a revised model of atmospheric $\mathrm{CO}_{2}$ over Phanerozoic time. Am. J. Sci. 301, 182-204 (2001).

37. McKanzie, N. R. et al. Continental arc volcanism the prinicpal driver of icehouse-greenhouse variability. Science 352, 444-447 (2016).

38. Berner, R. A. The rise of plants and their effect on weathering and atmospheric $\mathrm{CO}_{2}$. Science 276, 544-546 (1997).

39. Meinshausen, M. et al. The RCP greenhouse gas concentrations and their extensions from 1765 to 2300. Clim. Change 109, 213-241 (2011).

40. Rogner, H. H.- et al. in Global Energy Assessment-Toward a Sustainable Future. (eds Johansson, T. B. et al.) 423-512 (Cambridge University Press and the International Institute for Applied Systems Analysis, 2012).

41. Winklemann, R., Levermann, A., Ridgwell, A. \& Caldeira, K. Combustion of available fossil fuel resources sufficient to eliminate the Antarctic Ice Sheet. Sci. $A d v$. e1500589 (2015).

42. Lenton, T. M. et al. Millennial timescale carbon cycle and climate change in an efficient Earth system model. Clim. Dyn. 26, 687-711 (2006).

43. Zalasiewicz, J., Williams, M., Haywood, A. \& Ellis, M. The Anthropocene: a new epoch of geological time? Philos. Trans. R. Soc. A 369, 835-841 (2011).

44. Zeebe, R. M., Ridgwell, A. \& Zachos, J. C. Anthropogenic carbon release rate unprecedented during the past 66 million years. Nat. Geosci. 9, 325-329 (2016).

45. Yapp, C. J. \& Poths, H. Carbon isotopes in continental weathering environments and variations in ancient atmospheric $\mathrm{CO}_{2}$ pressure. Earth Planet. Sci. Lett. 137, 71-82 (1996).

46. Yapp, C. J. $\mathrm{Fe}\left(\mathrm{CO}_{3}\right) \mathrm{OH}$ in goethite from a mid-latitude North American Oxisol: estimate of atmospheric $\mathrm{CO}_{2}$ concentration in the Early Eocene 'climatic optimum'. Geochim. Cosmochim. Acta 68, 935-947 (2004).

47. Tabor, N. J. \& Yapp, C. J. Coexisting goethite and gibbsite from a highpaleolatitude $\left(55^{\circ} \mathrm{N}\right)$ Late Paleocene laterite: concentration and ${ }^{13} \mathrm{C} /{ }^{12} \mathrm{C}$ ratios of occluded $\mathrm{CO}_{2}$ and associated organic matter. Geochim. Cosmochim. Acta 69, 5495-5510 (2005).

48. Feng, W. \& Yapp, C. J. Paleoenvironmental implications of concentration and ${ }^{13} \mathrm{C} /{ }^{12} \mathrm{C}$ ratios of $\mathrm{Fe}\left(\mathrm{CO}_{3}\right) \mathrm{OH}$ in goethite from a mid-latitude Cenomanian laterite in southwestern Minnesota. Geochim. Cosmochim. Acta 73, 2559-2580 (2009).

49. Rustad, J. R. \& Zarzycki, P. Calculation of site-specific carbon-isotope fractionation in pedogenic oxide minerals. Proc. Natl Acad. Sci. USA 105, 10297-10301 (2008).

50. Tripati, A. K., Roberts, C. D. \& Eagle, R. A. Coupling of $\mathrm{CO}_{2}$ and ice sheet stability over major climate transitions of the last 20 million years. Science 326, 1394-1397 (2009).

51. Allen, K. A. \& Hönisch, B. The planktic foraminiferal B/Ca proxy for seawater carbonate chemistry: a critical evaluation. Earth Planet. Sci. Lett. 345-348, 203-211 (2012).

52. Lowenstein, T. K. \& Demicco, R. V. Elevated Eocene atmospheric $\mathrm{CO}_{2}$ and its subsequent decline. Science 313, 1928 (2006).

53. Pearson, P. N. \& Palmer, M. R. Atmospheric carbon dioxide concentrations over the past 60 million years. Nature 406, 695-699 (2000).

54. Pagani, M., Arthur, M. A. \& Freeman, K. H. Miocene evolution of atmospheric carbon dioxide. Paleoceanography 14, 273-292 (1999).

55. Pagani, M., Freeman, K. H. \& Arthur, M. A. Late Miocene atmospheric $\mathrm{CO}_{2}$ concentrations and the expansion of $\mathrm{C}_{4}$ grasses. Science 285, 876-879 (1999).

56. Pagani, M., Zachos, J. C., Freeman, K. H., Tipple, B. \& Bohaty, S. Marked decline in atmospheric carbon dioxide concentrations during the Paleogene. Science 309, 600-603 (2005).

57. Pagani, M. et al. The role of carbon dioxide during the onset of Antarctic glaciation. Science 334, 1261-1264 (2011).

58. Zhang, Y. G., Pagani, M., Liu, Z., Bohaty, S. M. \& DeConto, R. A 40-millionyear history of atmospheric $\mathrm{CO}_{2}$. Philos. Trans. R. Soc. A 371, 20130096 (2013).

59. Fletcher, B. J., Brentnall, S. J., Anderson, C. W., Berner, R. A. \& Beerling, D. J. Atmospheric carbon dioxide linked with Mesozoic and early Cenozoic climate change. Nat. Geosci. 1, 43-48 (2008).

60. Tipple, B. J., Meyers, S. R. \& Pagani, M. Carbon isotope ratio of Cenozoic $\mathrm{CO}_{2}$ : a comparative evaluation of available geochemical proxies. Paleoceanography 25, PA3202 (2010).

61. McElwain, J. C. \& Chaloner, W. G. The fossil cuticle as a skeletal record of environmental change. Palaios 11, 376-388 (1996).
62. McElwain, J. C. Do fossil plants signal palaeoatmospheric $\mathrm{CO}_{2}$ concentration in the geological past? Philos. Trans. R. Soc. Lond. B 353, 83-96 (1998).

63. Beerling, D. J. \& Royer, D. L. Fossil plants as indicators of the Phanerozoic global carbon cycle. Annu. Rev. Earth Planet. Sci. 30, 527-556 (2002).

64. Retallack, G. J. Greenhouse crises of the past 300 million years. Geol. Soc. Am. Bull. 121, 1441-1455 (2009).

65. Royer, D. L. in Causes and Consequences of Globally Warm Climates in the Early Paleogene (eds Wing, S. L., Gingerich, P. D., Schmitz, B. \& Thomas E.) 79-93 (Geological Society of America Special Paper 369, 2003).

66. Tralau, H. Evolutionary trends in the genus Ginkgo. Lethaia 1, 63-101 (1968).

67. Vörding, B. \& Kerp, H. Stomatal indices of Peltaspermum martinsii (Pteridospermopsida, Peltaspermaceae) from the Upper Permian Bletterbach Gorge and their possible applicability as $\mathrm{CO}_{2}$ proxies. Neues Jahrb. Geol. Paläontol. 248, 245-255 (2008).

68. Breecker, D. O., Sharp, Z. D. \& McFadden, L. D. Seasonal bias in the formation and stable isotopic composition of pedogenic carbonate in modern soils from central New Mexico, USA. Geol. Soc. Am. Bull 121, 630-640 (2009).

69. Montañez, I. P. Modern soil system constraints on reconstructing deep-time atmospheric $\mathrm{CO}_{2}$. Geochim. Cosmochim. Acta 101, 57-75 (2013).

70. Royer, D. L. Fossil soils constrain ancient climate sensitivity. Proc. Natl Acad. Sci. USA 107, 517-518 (2010).

71. Retallack, G. J. Refining a pedogenic-carbonate $\mathrm{CO}_{2}$ paleobarometer to quantify a middle Miocene greenhouse spike. Paleogeogr. Paleoclimatol. Paleoecol. 281, 57-65 (2009)

72. Cotton, J. M. \& Sheldon, N. D. New constraints on using paleosols to reconstruct atmospheric $p \mathrm{CO}_{2}$. Geol. Soc. Am. Bull 124, 1411-1423 (2012).

73. Ekart, D. D., Cerling, T. E., Montañez, I. P. \& Tabor, N. J. A 400 million year carbon isotope record of pedogenic carbonate: implications for paleoatmospheric carbon dioxide. Am. J. Sci. 299, 805-827 (1999).

74. Tabor, N. J., Yapp, C. J. \& Montañez, I. P. Goethite, calcite, and organic matter from Permian and Triassic soils: Carbon isotopes and $\mathrm{CO}_{2}$ concentrations. Geochim. Cosmochim. Acta 68, 1503-1517 (2004).

75. Montañez, I. P. et al. $\mathrm{CO}_{2}$-forced climate and vegetation instability during late Paleozoic deglaciation. Science 315, 87-91 (2007).

76. Doria, G. et al. Declining atmospheric $\mathrm{CO}_{2}$ during the late Middle Eocene climate transition. Am. J. Sci. 311, 63-75 (2011).

77. Beerling, D. J., Fox, A. \& Anderson, C. W. Quantitative uncertainty analyses of ancient atmospheric $\mathrm{CO}_{2}$ estimates from fossil leaves. Am. J. Sci. 309, 775-787 (2009).

78. Breecker, D. O. Quantifying and understanding the uncertainty of atmospheric $\mathrm{CO}_{2}$ concentrations determined from calcic paleosols. Geochem. Geophys. Geosyst. 14, 3210-3220 (2013).

79. Gradstein, F. M., Ogg, J. G., Schmitz, M. D. \& Ogg, G. M. (eds). The Geologic Time Scale 2012 (Elsevier, 2012).

80. Schaller, M. F., Wright, J. D., Kent, D. V. \& Olsen, P. E. Rapid emplacement of the Central Atlantic Magmatic Province as a net sink for $\mathrm{CO}_{2}$. Earth Planet. Sci. Lett. 323-324, 27-39 (2012).

81. R Core Team. R: A language and environment for statistical computing. Available at http://www.R-project.org/ (2015).

82. Bereiter, B. et al. Revision of the EPICA Dome $\mathrm{C} \mathrm{CO}_{2}$ record from 800 to 600 kyr before present. Geophys. Res. Lett. 42, 542-549 (2015).

\section{Acknowledgements}

We would like to dedicate this manuscript to the late Bob Berner for his seminal work in understanding the global carbon cycle. We are indebted to Gavin Schmidt and the readers and contributors of RealClimate.net for inspiring us to come up with this $\mathrm{CO}_{2}$ compilation and write this paper. We also thank the Royal Society for funding a Satellite Meeting at the Kavli Centre in 2011, 'Reconstructing and understanding $\mathrm{CO}_{2}$ variability in the past', at which the development of long-term compilations of $\mathrm{CO}_{2}$ was discussed. G.L.F. and D.J.L. acknowledge support from NERC (grant NE/I005595/1). Andy Ridgwell is thanked for supplying the $\mathrm{CO}_{2}$ emission scenarios from Winklemann et $a l^{41}$ and for his thoughts on silicate weathering. The manuscript was greatly improved by the thorough reviews of an anonymous reviewer, Tim Lenton and Ethan Grossman.

\section{Author contributions}

All authors conceived the idea for this manuscript, D.L.R. compiled the $\mathrm{CO}_{2}$ data set and G.L.F. performed the statistical analysis of the $\mathrm{CO}_{2}$ data. G.L.F. drafted the initial version of the manuscript and all authors contributed to the text.

\section{Additional information}

Supplementary Information accompanies this paper at http://www.nature.com/ naturecommunications

Competing interests: The authors declare no competing financial interests. 
Reprints and permission information is available online at http://npg.nature.com/ reprintsandpermissions/

How to cite this article: Foster, G. L. et al. Future climate forcing potentially without precedent in the last 420 million years. Nat. Commun. 8, 14845 doi: $10.1038 /$ ncomms14845 (2017).

Publisher's note: Springer Nature remains neutral with regard to jurisdictional claims in published maps and institutional affiliations. (c) (i) This work is licensed under a Creative Commons Attribution 4.0 International License. The images or other third party material in this article are included in the article's Creative Commons license, unless indicated otherwise in the credit line; if the material is not included under the Creative Commons license, users will need to obtain permission from the license holder to reproduce the material. To view a copy of this license, visit http://creativecommons.org/licenses/by/4.0/

(C) The Author(s) 2017 